\title{
La imagen de la Rusia del XIX en la pluma de Juan Valera y Mohamed 'Yad El-Ṭanțawy
}

\section{The Image of the XIXth century Russia in the texts of Juan Valera and Mohamed 'Yad El-Ṭanțawy}

\author{
Hala ABDEL SALAM AHMED AWAAD \\ Ain-Shams University \\ h.plenilunio@gmail.com
}

Recibido: octubre 2011

Aceptado: abril 2012

\section{RESUMEN}

En este artículo se presentan dos casos concretos de la visión que tienen dos personajes: Mohamed 'yad El-Ṭanțawy', egipcio y Juan Valera, español, de Rusia. Se pretende comparar la visión entre las imágenes que poseen ambos personajes de un país muy diferente a su cultura, a través de dos libros que tratan de sus impresiones y experiencias sobre este país: Regalo para inteligentes con las noticias de los países de Rusia y Cartas desde Rusia.

$\mathrm{Da}$ la coincidencia que ambos eran contemporáneos, mediados del siglo XIX, y, en cierto modo, compartían aficiones, la literatura.

Palabras clave: Mohamed 'yad El-Ṭanțawy, Juan Valera, Regalo para inteligentes con las noticias de los países de Rusia, Cartas desde Rusia, literatura del siglo XIX.

\begin{abstract}
In this paper, we will show two points of view of two authors, namely, Juan Valera, from Spain, and Mohamed 'yad El- Tanțawy, from Egypt, toward the Russia of the $19^{\text {th }}$ century. The purpose is to draw a comparison between the pictures of the two authors, each of whom comes from a culture distant from Russia, writing two books that include their impressions and experiences about Russia, namely: The Masterpiece of the Intelligent in the News of Russia, and Letters from Russia.

By coincidence, the two authors lived in Russia at the same time in the Mid $19^{\text {th }} \mathrm{C}$ and they have a common characteristic, which is literature.
\end{abstract}

Keywords: Mohamed 'Yad El-Ṭantawy, Juan Valera, The Masterpiece of the Intelligent in the News of Russia, Letters from Russia, $19^{\text {th }}$ C. literature.

SUMARIO: 0. Introducción, 1. Regalo para inteligentes con las noticias de los países de Rusia: Mohamed 'Yad El-Ṭanțawy, 1.1 Mohamed 'Yad El-Ṭanțawy (1810-1861), 1.2 El viaje a Rusia, 1.2.1 Itinerario, 1.3 El manuscrito, 2. Cartas desde Rusia: Juan Valera, 2.1 Juan Valera (1824-1905), 2.2 El viaje a Rusia, 2.2.1 Itinerario, 2.3 Las cartas desde Rusia, 3. Conclusión.

\footnotetext{
${ }^{1}$ La transcripción manejada en el trabajo corresponde al sistema español de la SEEA.
} 


\section{INTRODUCCIÓN}

Durante el siglo XIX, pocos son los árabes y españoles que visitaron Rusia, y, lejos de los informes de las misiones diplomáticas, menos son todavía los que dejaron escritas sus experiencias e impresiones de estos viajes. Las primeras impresiones literarias las encontramos en el libro de El-Tanțawy y de Valera.

En este trabajo se busca y se compara la imagen de Rusia que surge de las dos obras: Regalo para inteligentes con las noticias de los paises de Rusia y Cartas desde Rusia, de Mohamed 'yad El-Țanțawy y Juan Valera respectivamente; presentaremos a sus autores, itinerarios de sus viajes y puntos convergentes y divergentes.

Da la coincidencia que ambos eran contemporáneos, mediados del siglo XIX, y, en cierto modo, compartían aficiones, la literatura.

Y dado que el libro de Cartas desde Rusia es sobradamente conocido, y por el contrario, el manuscrito de El-Tanțawy hasta ahora ningún egipcio lo ha visto y menos un español, amén del largo período de tiempo que pasó éste en Rusia -desde 1840 hasta su muerte 1961- en el presente trabajo las citas del manuscrito de ElṬanțawy serán más extensas.

\section{REGALO PARA INTELIGENTES CON LAS NOTICIAS DE LOS PAÍSES DE RUSIA: MOHAMED 'YAD EL-ṬANṬAWY}

La personalidad de este «Consejero» destaca sobremanera en la historia de la Cátedra de Lengua y Literatura árabes durante más de un siglo, primero en la Universidad de San Petersburgo, antigua Petrogrado y Leningrado tras la muerte de Lenin. ${ }^{2}$

\subsection{MOHAMED 'YAD EL-ṬANȚAWY $(1810$ - 1861)}

La fuente más importante sobre los datos de la vida del El-Tantawy antes de su viaje a Rusia en 1840, es su propio manuscrito. Parece ser que El-Tantawy lo escribió como Curriculum Vitae al arabista Fresnel. La importancia de la vida de El-Tanțawy no radica sólo en su lado histórico, sino el histórico-social, pues refleja con exactitud el interés de los doctos árabes en la primera mitad del siglo XIX cuando, todavía, reinaba el movimiento tradicional, antes de la aparición de la literatura árabe moderna.

Mohamed ben S'd ben Soliman 'yad El-Marhomy El-Ṭanțawy El-Šaf'i nace en Negrid $^{3}$ en $1810(1225 \mathrm{H})$. En su infancia aprende el Corán. A los 13 años, se traslada a El Cairo para seguir estudiando y preparándose para El-Azhar. Allí estudia interpretación, jurisprudencia islámica, lógica, retórica y oratoria.

Cabe destacar que El-Azhar siempre fue cuna de ilustración en Egipto y el mundo islámico en donde se graduaron grandes figuras cuya labor jalona la historia de la ciencia del pensamiento moderno, como es el caso de Ref'h El-Ṭahțawy,

\footnotetext{
${ }^{2}$ Krackovski, J: La vida de Mohamed 'yad El-Tanțawy. Leningrado, ed. Akdemhh, 1929, p. 9. Traducción Kaltum Oda. La traducción al español es mía.

${ }^{3}$ Una ciudad de Egipto de la provincia de El Garbeya.
} 
amigo de El-Tanțawy, y figura cumbre del auge científico y cultural al que llegó Egipto en tiempo de Mohamed 'li Pachá.

Apenas cumplidos 18 años, y por falta de recursos económicos tras la muerte de su padre y con el permiso de su maestro Mostafa El-Qenawy ${ }^{4}$, enseña hadiz, dando señales de su madurez intelectual. Durante la carrera universitaria, siendo también aventajado discípulo de Hassan El- taar $^{5}$ e Ibrahim El-Bagury ${ }^{6}$, se pone de manifiesto su inclinación por la literatura y la crítica literaria por lo que se convierte en uno de los pioneros de este campo.

Gran conocedor de la lengua árabe clásica, se había puesto El-Ṭanțawy en contacto con destacados miembros de las misiones extranjeras que los proyectos de Mohamed 'li habían atraído al país y que estaban en la imperiosa necesidad de aprender árabe. Su primer discípulo es $\mathrm{F}$. Fresnel ${ }^{7}$, y a él debe El-Tanțawy su aprendizaje del francés; antes de salir a Rusia, se dio cuenta que el conocimiento de la cultura europea le sirvió mucho.

Con el paso del tiempo adquirió El-Ṭanțawy mucha fama entre la colonia europea, así pues, tuvo otros discípulos ${ }^{8}$ : el orientalista y médico francés Perron, los alemanes Weil y Pruner y los dos orientalistas políticos rusos: Mojin y Frähn', los cuales le sugirieron viajar a Rusia. Solicitada una licencia para trasladarse a este país, Mohamed 'li le recibe y le sugiere estudiar la lengua rusa a fondo.

Y así, en 1840, el Zar de Rusia dio permiso para que El-Tanțawy pasara a formar parte del personal docente del departamento de Ciencia y Educación que dependía del Servicio de Exteriores del Imperio ruso.

\subsection{EL VIAJE A RUSIA}

\subsubsection{ITINERARIO}

Sin lugar a dudas, para El-Tanțawy, el viaje a Rusia fue un hecho crucial de su vida: era la primera vez que salía fuera de Egipto.

El sábado 16 de marzo de 1840 sale de El Cairo rumbo a Alejandría en un esquife y navega por el Nilo. Allí se entrevista con el Cónsul General de Rusia. Tras haber realizado parada en Creta y Esmirna, llega a Estambul donde tiene que pasar algunos días en cuarentena. Acto seguido visita al embajador de Rusia. El 23 de abril, emprende el viaje, esta vez a Odesa y se inicia en el estudio de la lengua rusa

\footnotetext{
${ }^{4}$ Uno de los maestros de El-Ṭanțawy, e Imam de la mezquita El Badawi en Tanta.

${ }^{5}$ Hassan El- ${ }^{6}$ taar (1776-1835): fue Scheihk de El-Azhar, y a él se debe la edición del periódico La Gaceta Egipcia.

${ }^{6}$ Ibrahim El-Bagury (1783-1861): fue Scheihk de El-Azhar.

${ }^{7}$ Fulgence Fresnel (1795-1855): diplomático y orientalista francés. Entre sus obras importantes Cartas sobre la historia de los árabes antes del islam.

${ }^{8}$ Para mayor información vease al respecto Krackovski, J: La vida de Mohamed 'yad El-Ṭantawy. Leningrado, ed. Akdemhh, 1929

${ }^{9}$ Rudolf Frähn (1812-1858): el hijo mayor del fundador del museo Asiático en San Petersburgo y su director por largo tiempo, heredó de su padre su pasión por el orientalismo.
} 
con N. Mojin. En Odesa vuelve a pasar unos días por la cuarentena, aprovecha para mejorar su conocimiento del ruso. Tras una estancia de un mes, deja la ciudad para dirigirse a Kiev, Mohlove, y finalmente a San Petersburgo, donde se instala hasta su fallecimiento el 29 de octubre de 1861.

\subsection{EL MANUSCRITO}

La estancia de El-Ṭantawy en Rusia, supuso un hecho de gran trascendencia, no sólo a nivel personal, sino para el arabismo ruso también.

A pesar del escaso número de los intelectuales rusos en los años 1830-1840, el interés por el Oriente Próximo alcanzaba cuotas que más tarde difícilmente superaría. ${ }^{10}$

El manuscrito de El-Țanțawy trasciende la pura descripción de su vida por su interés literario, cultural e histórico. Había dos copias del mismo: una en Estambul - estaba en la mezquita de Reda Pachá en Romly Kesar y más tarde pasa a la Biblioteca de la Universidad ${ }^{11}$-, la otra, se conservaba en Leningrado, pero desapareció después de la segunda guerra mundial.

El manuscrito se compone de 194 páginas. El autor lo inicia con un índice, describiendo todo el contenido del manuscrito, está sin paginación; después viene el título: Regalo para inteligentes con las noticias de los países de Rusia. En la página siguiente aclara la importancia de la ciencia y el motivo de su viaje, su nostalgia y pena por dejar los familiares y amigos, y esto lo lleva a explicar el motivo de escribir este libro, y que lo escribió a petición de sus compañeros.

Después viene la introducción, ésta ocupa la cuarta parte del libro, no consta ningún título, mas en el índice menciona 34 subtítulos. Comprende su viaje desde El Cairo a San Petersburgo, y nos da claros indicios de los primeros años de su estancia en esta ciudad (1840-1849) y de sus aficiones, amén de recuerdos de su primer viaje a Egipto en el verano de 1844.

Luego, la primera parte, es de poca extensión, trata la génesis de Rusia. La segunda aborda la historia de Pedro el grande y San Petersburgo: altitud, dimensión de la ciudad, clima, congelación y descongelación de su agua, los ríos, inundaciones, Pedro I, el actual Zar, etc. Abarca esta parte 170 subapartados. Así que, ambas partes ocupan la mitad del manuscrito.

La tercera y última parte, está dividida a su vez en diez capítulos que tratan: los usos y costumbres de los rusos, vestimenta, religión, bautismo, fiestas, bailes y entretenimientos, prosperidad en la ciencia y en las artes, casas de los rusos y lenguas.

El-Ṭantawy con su presencia apoyó el incipiente arabismo ruso, así como aportó manuscritos a las Bibliotecas Nacionales finlandesas, alemanas y rusas. Y en éstas últimas se guardan todavía manuscritos corregidos, con explicaciones, citas o notas finales por mano del propio El-Ṭantawy que, a su vez, hace referencia a la Biblioteca imperial:

\footnotetext{
${ }^{10}$ Krackovski, J, p. 53.

${ }^{11}$ El-Ṭantawy, Mohamed 'yad: Regalo para inteligentes con las noticias de los países de Rusia. Manuscrito n. 766. Biblioteca de la Universidad de Estambul.
} 
Contiene libros de todas partes, también nuestros, contiene asimismo manuscritos. Hay una gran sala donde los libros están muy bien guardados, está permitido la consulta, la copia, mas está prohibido trasladar los libros a otro sitio sin un permiso especial (p113). ${ }^{12}$

Más adelante veremos cómo Valera pone el mayor interés en hablar también de la Biblioteca Imperial y el fondo bibliográfico que atesora.

Como no podría ser de otra manera, tanto El-Ṭanțawy como Valera se interesaban sobremanera por la prensa de San Petersburgo, y sobre todo la prensa literaria. Comenta El-Ṭantawy:

Se editan muchos periódicos tantos que su número ha sobrepasado el límite normal; algunos son diarios tales como «Palmeras del Norte», «Episodios», «Crónicas de Petersburgo» todos en lengua rusa, que acogen, junto con las noticias, algunos aspectos literarios. Otros son mensuales tales como «El patriota», «Escritura nacional», «El contemporáneo» y la «Gaceta Literaria», que edita un libro cada mes y seis tomos anuales. Consisten en libros escritos por autores actuales, salen en forma de periódicos para mayor difusión. Asimismo, hay publicaciones mensuales para niños (...). Junto con la prensa occidental procedente de Francia, Alemania y otros países, se editan periódicos en francés y alemán (p.187).

También señala El- Tanțawy que por eso los rusos aprenden muchos idiomas a parte del ruso.

Pero esto no agota ni mucho menos el texto de El-Ṭanțawy, sino todo lo contrario. A la manera y usanza de los grandes viajeros y geográficos, el escritor describe al detalle todo cuanto veía durante el viaje: la navegación por el Nilo hasta Alejandría y por el mar hasta Creta, Esmirna, Estambul, Odesa, las cuarentenas que tuvo que pasar.

Una vez en tierra rusa, lo describe todo, el espacio urbano y la campiña, las arquitecturas populares y los grandes palacios y edificios imperiales. Cuando describe una ciudad lo describe como un auténtico geógrafo: el espacio urbano, las calles, los ríos, la altitud, las estaciones del año, las cosechas, las fiestas religiosas y oficiales, etc.

Se acerca a las clases bajas y describe las precarias condiciones en las que viven, Asimismo, dedica un espacio a la genealogía del actual Zar, las Academias Científicas y el museo de Ciencia y Biología, a las novedades musicales, el correo a caballo, la construcción de nuevas catedrales, la entronación de Catalina Zarina, etc.

El estilo literario del manuscrito reúne las principales características de la época. Recuerda mucho tanto a las crónicas como los libros de miscelánea de otros momentos, compuesto en prosa rimada con continuas incrustaciones poéticas de cosecha propia o de otros clásicos o contemporáneos. Un estilo culto con frecuentes visitas al refranero clásico, a la poesía popular, a la maravilla y a la fantasía del acervo egipcio árabe. Sin contar el principal signo estilístico de este libro que es la descripción, puesto que el carácter geográfico predomina en el texto aparte de otros, como pueden ser lo historiográfico o lo sociológico:

${ }^{12}$ El-Ṭanțawy, Mohamed 'yad: Regalo para inteligentes con las noticias de los países de Rusia, Universidad de Estambul, Manuscrito n. 766, Estambul, 1850, repografía en CD, la traducción es mía. 
Nicolás I, el Zar actual, ha seguido la senda de sus antepasados y se lo ha dejado difícil a sus sucesores. Se puso a rematar la construcción de la ciudad y del reino: el teatro Mijaíl y sobre todo el de Alejandra, que lleva el nombre de la zarina y que hace años fue presa de un incendio aunque con muy pocas consecuencias, son dos buenas muestras de ello. Asimismo, construyó calles (...). Una obra admirable supone el haber revestido de madera la Avenida Nevski para facilitar el suave deslizamiento de los coches. Ordenó talar los árboles de esa avenida y asfaltar el sitio que ocupaban y así ganar mucho espacio (...). Enfrente del palacio del Invierno, ordenó levantar una majestuosa columna de piedra rosada, en memoria de su hermano Alejandro I (p.148).

Interesa también, tratándose de una crónica de viaje el estilo desenfadado cuidadosamente elaborado con el fin de evitar cualquier aburrimiento o distracción. Ocurrencias, anécdotas, humor y sobre todo grandes dotes de contador de historias son algunos rasgos que van en esta dirección:

Las mujeres ocupan el primer plano. Son las que llevan los asuntos de la casa y arreglan los defectos del marido: si en casa del hombre no hay una mujer libre que lo cuide, lo perderá todo. En el comedor, a las mujeres se les reserva un lugar destacado. Y son preferentemente las que inician la comida, lo mismo ocurre en la iglesia o en el baile (p.191).

Descolla, asimismo, la gran labor de documentación que se deja ver a veces, sin asomo de duda, en gran parte del libro:

Los primeros pobladores de esos grandes espacios geográficos, espesuras y campos de cultivo eran de origen eslavo, «remeros y zapateros». Pero esto fue hace muchísimo tiempo. Eran paganos adoraban el sol, la luna, a ídolos. Adoraban imágenes que ellos fabricaban, no sabían ni leer ni escribir (p.52).

\section{CARTAS DESDE RUSIA: JUAN VALERA}

Pasaron por la tierra de Rusia, de un extremo a otro, varios españoles: Abu Hamid el Granadino (1080-1170); el sacerdote Pedro Cubero (1640-1696); el destacado militar y político el Almirante Josep de Ribas (1749-1800); el músico y compositor Vicente Martín y Soler (1754-1806), rival de Mozart; Agustín Betancourt y Molina (1758-1824); o Juan Van Halen (1778-1864).

Sin embargo, pocos han dejado testimonio sobre la cultura rusa, y son menos aún los que han dejado escritas sus impresiones de estos viajes. En cambio Valera dejó sus experiencias e impresiones en sus Cartas que constituyen una excepcional fuente para el estudio de la Rusia inmediatamente posterior a la guerra de Crimea.

\subsection{JUAN VALERA (1824 - 1905)}

Juan Valera y Alcalá Galiano ${ }^{13}$ novelista, poeta, periodista, traductor, académico, político y diplomático.

\footnotetext{
${ }^{13}$ Para más información sobre la vida de Valera véase:
} 
Durante la vida de Valera, España intentaba imponer las nuevas tendencias de desarrollo industrial luchando contra una tradición enraizada de carácter agrícola; la burguesía, a su vez, era débil ante el resto de la sociedad, así que buscó alianza con el ejército, y como consecuencia de esta alianza el país carecía de un verdadero Gobierno liberal.

Valera hace la carrera de Derecho en Granada y Madrid. Al terminar sus estudios se traslada a la corte. En 1847 obtiene el puesto de agregado sin sueldo en Nápoles bajo el duque de Rivas. Sin embargo, en 1849, renuncia a su puesto en la embajada de Nápoles. Unos meses después se le nombra agregado de Lisboa, y se traslada desde allí a Rio de Janeiro. Vuelve a Madrid en noviembre de 1853. Durante las décadas siguientes divide su tiempo entre la diplomacia, la política, el periodismo y la literatura.

Desde todos los puntos del globo escribía Juan Valera cartas a su familia y amigos. La enorme cantidad de cartas confirma el rechazo de Valera a la soledad y su deseo de intercambio de ideas. Entre 1855-1856 sirve de jefe de legación en Dresde, y desde finales de 1856, (10 de diciembre), hasta mediados de 1857, (6 de junio) es destinado a Rusia como Secretario de la misión extraordinaria del Duque de Osuna para felicitar, en nombre de Isabel II, a Alejandro II, recién coronado Zar de todas las Rusias. En aquellos años Valera es ya conocido y respetado en los círculos literarios.

Sus cartas dirigidas a su familia constituyen un fiel testimonio de lo que ocurre en España durante ese período, y son de especial importancia para conocer la génesis de los movimientos ideológicos y políticos del momento. Asimismo, revelan un carácter realista y objetivo, capaz de analizar los secretos de la política, al igual que ocurriera más tarde con el desastre del 98 en el que Valera parece anticipar el enfrentamiento con los Estados Unidos.

Valera abandona definitivamente la vida diplomática, y tras el decaimiento físico y la ceguera, el 18 de abril de 1905 Valera deja de existir.

\subsection{EL VIAJE A RUSIA}

\subsubsection{ITINERARIO}

La ruta que recorre Valera por causa de la misión hasta San Petersburgo es la siguiente: Madrid - París - Bruselas - Münster - Berlín - Varsovia - San Petersburgo.

La misión, que emprende en una difícil estación del año, hace largas paradas y asiste a una cantidad enorme de recepciones, se realiza todo el trayecto en el ferrocarril que terminaba en la frontera rusa.

Abud, Eduardo: «La vida amorosa de Juan Valera conocida a través de su obra epistolar». Revista de estudios lingüisticos y literarios, Volumen 2, n. 1, Primavera 2004.

Amorós, Andrés: La obra literaria de Don Juan Valera: la música de la vida. Castalia, Madrid, 2005.

Azaña, Manuel: La vida de Don Juan Valera. Delegación de cultura, Granada, 2005.

Bravo-Villasante, Carmen: Vida de Juan Valera. Ediciones de Cultura Hispánica, Madrid, 1989.

Revilla, Manuel de la: «Don Juan Valera». Revista Contemporánea. Año IV, n. 51, tomo XIII, volumen I, Madrid, enero de 1878, pp. 487-497. 
"Viajamos a lo príncipe" $\left(p\right.$. 33) ${ }^{14}$, así califica Valera la primera parte de la ruta (París - Varsovia). Sin embargo, le recibe Polonia “a 14 bajo cero Réaumur” (p.44); y sigue el viaje para Valera "de diversión en diversión, de fiesta en fiesta, vistiéndome y desnudándome y acompañando al duque" (p.52), y durante su peregrinación, como lo dice "no hemos dormido una sola vez en cama, sino siempre vestidos" (p.54), con pequeños descansos en tres o cuatro puntos, atravesando en trineos "una llanura sin árboles, que se extendía indefinidamente, confundiéndose a lo lejos con el aire"(p.54). Así pues, pasaba el tiempo la misión en la ruta hasta al fin su destino que para Valera "es inmenso, y por lo poco que he visto, me gusta más que París"(p.62).

Sin embargo, este viaje le puso en contacto con un gran imperio agrícola. Desde Pedro el Grande los zares habían luchado por la occidentalización de los dirigentes, pero el imperio seguía viviendo en unas condiciones primitivas.

\subsection{LAS CARTAS DESDE RUSIA ${ }^{15}$}

La epístola fue una de las formas predilectas del escritor de Cabra. Un breve repaso de su obra literaria registra más de un volumen en forma epistolar desde su famosa novela Pepita Jiménez hasta dos volúmenes que recoge su obra. Parece ser que al autor se siente cómodo componiendo epístolas, habida cuenta de la gran maestría y el gran cuidado del autor a la hora de dibujar tantas escenas y cuadros de todo cuanto ve o escucha, y cómo inserta en sus cartas cuánta información recaba. Y si en su obra narrativa, como en Pepita Jiménez, ofrece un buen ejemplo del recurso de la epístola como signo narrativo, aquí, en este cuaderno de viaje, también en formato epistolar, mantiene el interés y la curiosidad del lector hasta unos límites insospechados.

Rusia para Valera es, ante todo una novedad, una novedad rodeada de lujo y exotismo que despierta magníficamente en él una extraordinaria avidez de creatividad epistolar ${ }^{16}$.

Para Valera, el viaje a Rusia abre un horizonte de auténtica experiencia intercultural. Aún enclavada en unas coordenadas harto diferentes de las europeas y occidentales, la Rusia del Zar Alejandro II brindaba a Valera y a la cultura española nuevos aspectos y matices, en donde la comparación constante es un recurso casi obligado para una mente tan culta, abierta, como imbuida en detectar todos los aspectos y síntomas de una cultura diferente.

La Rusia de la segunda mitad del siglo XIX supone todo un descubrimiento paraa un Valera preocupado por una serie de ideas y aspectos que habían sido

\footnotetext{
${ }^{14}$ A partir de aquí se cita de: Valera, Juan: Cartas desde Rusia. Miraguano eds., Madrid, 2005.

${ }^{15}$ Para más información sobre el viaje y las cartas de Valera véase:

Revilla, Manuel de la: «Don Juan Valera». Revista Contemporánea. Año IV, n. 51, tomo XIII, volumen I, Madrid, enero de 1878, pp. 487-497.

Casenave, Marieta Cantos: Juan Valera y la magia del relato decimonónico. Univ. De Cádiz, Cádiz, 1998. Chopin: Historia de la Rusia. Guardia Nacional, Barcelona, 1939.

Giraldo, Manuel Lucena y Juan Pimentel: Diez estudios sobre literatura de viajes. CSIC, Madrid, 2006. Valera, Juan: Correspondencia. Aguilar, Madrid, 1958.

${ }^{16}$ Encinas, Ángel Luis: Juan Valera: Cartas desde Rusia. Miraguano ediciones, Madrid, 2005, p. 13.
} 
reflejados en otras obras suyas: el saber, el conocimiento, la literatura, las bibliotecas, las artes plásticas, la enseñanza, la vida social, la condición de la mujer, junto con otros aspectos subjetivos que afectan a la experiencia personal y que se recortan ante un paisaje majestuoso, solemne a la par que frívolo y ocioso.

El plano subjetivo de una buena parte de las cartas marca una línea subterránea paralela a una crónica o a una epístola de viaje.

Valera se quedó maravillado "del lujo asombroso de los grandes señores rusos" (p.86), y sus cartas están llenas de descripciones de los diversos palacios que visitaba y de las abundantes comidas: "Cada día tenemos una comida y cada día vemos un nuevo y magnífico palacio” (p.87).

Las cartas que estaba destinadas a Leopoldo Augusto de Cueto, están llenas de erudición y de observaciones sobre política, creencias religiosas y costumbres, si bien desprovistas de noticias literarias, debido sin duda a desconocer la lengua rusa.

Para Juan Valera la democracia aparece como carácter de enfermedad social: es cierto que los hombres son semejantes entre sí, pero es una equivocación deducir de tal aserto una identidad entre ellos.

El carácter aristócrata e individualista de Valera temblaba ante la posibilidad de hundirse en el anonimato y perder la constancia que hace del hombre un arco tenso dirigido hacia metas ideales por el enorme crecimiento de población que traía los tiempos modernos y la amenaza de la plebe al Poder intentando apoderarse de él y desterrar a las antiguas clases dirigentes: "La aristocracia de sangre terminará, a mi ver, en todas partes. La clase media será la soberana, y esta clase media será muy numerosa..." (p.205). Así que los contrastes que ha ido observando a lo largo del camino, la extrema rudeza de algunos individuos rusos y la exagerada finura y exquisitez de otros, dan pie a la siguiente meditación:

Pero esto mismo me da aún más alta idea del poder de este imperio. ¿Qué fuerza no puede mandar esta poderosa aristocracia refinadamente culta, capaz e inteligente, teniendo a su disposición esta masa ruda y enérgica, que manda a puntapiés y a pescozones? Si el correo nos sacaba los coches del atolladero ¿qué no podrán mover estos hombres el día que quieren? (p.61)

Como miembro de la misión diplomática Juan Valera tuvo acceso a los círculos más elitistas de Rusia. En los palacios maravillosos de San Petersburgo sólo se oía el francés; los músicos más célebres interpretaban en sus salones; los políticos pertenecían a una clase educada en el extranjero. La Corte rusa le parecía estar compuesta casi en su totalidad por los príncipes, cuyo número podía solo competir con el de los generales. Comenta los grados de aristócratas y nobles, que vamos a comparar con lo que dice El-Ṭanțawy. Valera:

Aquí la aristocracia, esto es, la nobleza, porque una aristocracia en el sentido estricto de la palabra ni la hay ni sería compatible con la autocracia del zar, no estaba llamada exclusivamente a los empleos públicos; antes bien, los empleos públicos son los que daban y dan inmediatamente la nobleza personal a quien los desempeña. En el momento en que un ruso, aunque sea de la familia más humilde, puede vestir un uniforme y ceñir una espada, ya es tan noble como el que más (p.139). 
En el libro de El-Ṭanțawy la jerarquía y la nobleza están representadas de la siguiente manera:

La primera categoría: los nobles, es un título hereditario, los que gozan del mismo son muy privilegiados, pueden comprar terrenos, esclavos, tienen acceso a las reuniones de la nobleza. Un poseedor de un título nobiliario a la hora de casarse con una mujer del pueblo le confiere a ésta la categoría de noble. Esta categoría a su vez se divide en: a- Nobleza rancia: a ella pertenecen los que llevan el título desde antes del reinado de Pedro el grande, y están inscritos en el libro tercero; b- Nobles: con título después de la época de Pedro, cuyos nombres están en el libro sexto.

La segunda categoría: los nobles sin título hereditarios y son aquellos extranjeros o empleados que fueron condecorados por el Zar, y desde entonces se consideran nobles hereditarios y gozan de posesión de tierras y esclavos rusos.

Tercera: los mercaderes: no se consideran en Rusia entre los nobles.

Cuarta: los villanos si llegan a ser mercaderes y entran en servicio militar reciben el mismo tratamiento.

Quinta: los campesinos, si entran en servicio reciben el mismo tratamiento.

Sexta: los cosacos, y estos tienen que permanecer en servicio durante 15 años.

Séptima: los esclavos. Los esclavos solo llegan a ser nobles después de liberarse y cuando llegan a ser cosacos (p. 150).

Para Valera el cristianismo fue distinto a las religiones antiguas, no sólo por su origen revelatorio, sino por su función, pues vino y separó lo espiritual de lo temporal. Así que Valera distingue separados dos planos en los que se desarrolla la existencia del hombre: el más elevado es el espiritual y de él debe cuidar la Iglesia; el otro plano, material, depende del Estado. Reconoce Valera todo lo que de positivo se debe al cristianismo y que la fe da la certeza y la seguridad.

Nos explica Valera cómo se adoptó en Rusia el cristianismo ortodoxo como religión oficial del Estado, al mismo tiempo tomaremos nota de lo que dijo ElTanțawy acerca de lo mismo. Dice Valera:

Se cuenta que cuando el Zar Vladimiro, después de haber tenido un disgustillo con Pernn ${ }^{17}$, se decidió a plantarle y a tomar otro dios para los rusos, los búlgaro, aquellos terribles guerreros que dieron cierto vicio abominable en muchas lenguas de Europa, trataron de que se hiciera mahometano con ellos; pero la falta de pompa en el culto, la necesaria abstinencia al vino y, sobre todo, la circuncisión, disgustaron a Vladimiro de la religión de Mahoma. Entonces envió a Constantinopla emisarios que volvieron maravillados de la grandeza y suntuosidad que habían visto en el templo que levantó Justiniano a la Eterna Sabiduría. Vladimiro, al oírlos, determinó bautizarse y que se bautizasen sus súbditos, y desde entonces son los rusos cristianos (p.142).

Dice El-Ṭantawy:

Eran paganos hasta que se convirtieron al cristianismo de los griegos en época de Vladimiro. Sin embargo, el Patriarca no es el único jefe, como el Papa en Roma, y el Emperador es jefe de la Iglesia, como el Sultán para los musulmanes. Bajo del mando del

${ }^{17}$ Perún: Dios de la guerra en la mitología rusa y eslava, equivalente al Wotán u Odín de la mitología escandinava y al Júpiter de la mitología romana. 
Emperador sirven tres patriarcas y varios clérigos... Pequeña es la diferencia entre la secta de los rusos y de los latinos: éstos suponen que Espíritu Santo procede del Padre y del Hijo, mientras aquellos suponen que el Espíritu Santo procede sólo del Padre (p.161).

Asimismo, Valera, en otras ocasiones mantiene una actitud sardónica frente al espíritu de religiosidad de los rusos:

En cambio la nación católica que entraba ahora en la lucha se unía con los herejes y peleaba por esos mismos grandes enemigos del hombre cristiano. Ilustres prelados de esta nación declaraban, no obstante, santa esta guerra, como si se tratase de una cruzada contra infieles. ¿Son acaso más conformes con nuestra fe las doctrinas de Lutero y de Calvino, o la sensual religión de Mahoma, que el símbolo de la Iglesia griega, que no se diferencia del nuestro sino en negar la autoridad del Papa y en suponer que el Espíritu Santo procede sólo del Padre y no igualmente del Padre y del Hijo?(p.171).

Pero pronto se arrepiente de lo dicho:

Querido amigo mío: En mi última carta dije a usted una infinidad de picardías contra la religión de este pueblo, y hoy me arrepiento y retracto de haberlas dicho... Estoy no sólo dispuesto a cantar mil veces la palinodia, sino maravillado y enternecido, además, de cuán religiosos son los rusos, y de las bellas cosas que he visto en estos días (p.281).

Valera, por su parte, en muchas ocasiones menciona La Biblioteca, el número de libros y manuscritos que contiene:

Anteayer estuve en la Biblioteca imperial, contiene hoy cerca de 70.000 volúmenes (...) Otra sala contiene los manuscritos, en número 20.000: latinos, griegos, árabes, persas, rusos, alemanes, franceses y españoles.

En un momento refleja las dudas y la mirada escéptica de un intelectual católico embarcado en una de las tareas diplomáticas que tuvo que desempeñar a lo largo de su carrera. No era de extrañar que se dirigiese a la Biblioteca Imperial y se interesase por su tesoro bibliográfico y, de paso, esbozar algunos otros comentarios sobre el Evangelio y la mala traducción:

De los nuestros vi la traducción española del Evangelio apócrifo de San Bernabé apóstol, que un tal Juan Maxin tradujo también en italiano. (...)yo no sé de cierto si el Evangelio traducido por Juan Maxin es el mismo que traduce el español o es otro, si existe en árabe o en alguna lengua sabia el original del uno o de los dos Evangelios, dado que haya dos, y si el traductor español le inventó o le tradujo con intenciones meramente literarias, o con el fin de seducir a las gentes y de inclinarse al islamismo, porque el falso evangelista llama a Cristo profeta y no Hijo de Dios, y predice la venida de Mahoma y defiende la circuncisión y la abstinencia de ciertos manjares y bebidas. (p.139)

En el caso de Valera, siempre se muestra dubitativo ante lo que pasa a su alrededor, también en materia de publicaciones y prensas culturales. Se lamenta porque no acaba de tener idea mejor del movimiento periódico y cultural en San Petersburgo, y ello por no saber ruso.

Sus cartas conforman un testimonio indispensable y vivo para entrar en contacto con los conocimientos que Valera posee de la cultura europea. 


\section{CONCLUSIÓN}

En el caso de Valera era una etapa más en su carrera diplomática, antes estuvo en Nápoles, Rio de Janeiro y Lisboa. Además, durante sus meses de estancia en San Petersburgo, estuvo condicionado por el carácter diplomático de su misión. Por un lado, su trato diario se reducía a la alta sociedad de San Petersburgo, por otro, él mismo lamentaba profundamente no haber podido aprender ruso para estar cerca del pueblo y del pulso cultural de aquella sociedad.

En lo que atañe a El-Ṭantawy, la naturaleza del viaje fue otra. En primer lugar, su presencia en San Petersburgo fue demandada por intelectuales rusos que pensaban fundar los cimientos de una escuela de arabismo ruso. Antes de emprender el viaje ElTanțawy fue recibido por Mohamed 'li Pachá que apoyaba su misión como puente entre dos culturas. En segundo lugar, su larga estancia en tierras rusas (21 años) y haberse mezclado con el pueblo llano, había cimentado sus conocimientos sobre la sociedad rusa en general, y la de San Petersburgo en particular.

Asimismo, habría que subrayar que este viaje y esta larga residencia fuera de Egipto suponían la primera y única vez que El-Tantawy abandonaba Egipto. Por lo tanto Regalo para inteligentes supone un manual sobre San Petersburgo: el clima, la población, el trazado arquitectónico, las clases sociales, la vida cultural, el aparato administrativo, las categorías sociales, la vida en palacio, etc., etc.

En el caso de Valera, éste ha podido en tan poco tiempo dar una excelente idea de la vida en palacio, la nobleza, la élite social y cultural de San Petersburgo.

Se observa en ambos escritores un arraigado sentido religioso: uno católico y el otro musulmán. En un principio ello suponía una barrera para entender una religiosidad tan compleja como la rusa. Aún así, al final, vemos que el bagaje cultural de cada uno y el espíritu universal que las caracterizaba a ambos les hizo entender y hasta reconocer la poca idea que a veces tenían de la Rusia ortodoxa, sobre todo Valera.

El-Ṭanțawy aprendió el ruso en muy poco tiempo, por esto pudo integrarse en la sociedad rusa muy pronto, sin embargo, Valera, por no saber ruso y por haberse dedicado a la vida nocturna rusa y a los saraos y las fiestas, a menudo se sentía aburrido y hasta pensaba que no merecía el sueldo que ganaba por lo que quería volver a Madrid.

Un rasgo común a ambos textos, que no deja de asomar entre líneas, es la nostalgia de ambos autores por sus respectivas patrias.

Es un signo estilístico que confiere preciosismo literario a ambos textos, sin mencionar el doble registro que hay en los textos consistentes en las continuas comparaciones que hace el autor entre lo que ve y lo que ha dejado atrás en su patria natal. Nostalgia, doble registro, poesía, ocurrencias, estilo depurado, son algunos de los muchos aspectos de ambos trabajos, por otra parte muy atractivos por la forma que elige cada autor a su texto. Valera, en forma epistolar y ElTantawy que prefiere la de los libros de viaje.

Como colofón, Regalo para inteligentes con las noticias de los países de Rusia y Cartas desde Rusia tienen un denominador común: Rusia y dibuja el país de mediados del siglo XIX, desde dos perspectivas ora divergentes, ora convergentes, al mismo tiempo complementarias. 